\title{
Topography and Morphology of the Bovine Cranial Cervical Ganglion and its Branches
}

\author{
Topografía y Morfología del Ganglio Cervical Craneal Bovino y sus Ramos
}

\author{
Jamal Nourinezhad*; Yazdan Mazaheri* \& Sedigheh Saberifar**
}

NOURINEZHAD, J.; MAZAHERI, Y. \& SABERIFAR, S. Topography and morphology of the bovine cranial cervical ganglion and its branches. Int. J. Morphol., 34(2):545-556, 2016.

SUMMARY: A detailed submacroscopic anatomical study of the cranial cervical ganglion (CCG) and its branches with its adjoining structures was carried out by examining 14 halves of seven heads of Holstein cattle under a magnifying lens to provide comprehensive descriptions with color photographs of the location, relation to neighboring structures, morphometry, and morphology of CCG and its branches. Our results were compared with previously nerves including jugular nerve; internal and external carotid nerves extremely, obtained morphological data on CCG in other ungulates to clarify the detailed comparative anatomy of CCG among them. The morphology of CCG and its branches in bovine was significantly and tangibly different from that of in other reported ungulates, especially in the direction of the ventral and dorsal poles of CCG being caudodorsal and rostroventral respectively, being larger and slightly more rostral, covered laterally by the dorsal part of the stylohyoid bone and caudal stylopharyngeus muscle, close relation of CCG to the medial retropharyngeal lymph node, wider distributions of external carotid nerve and its plexus to the adjacent arteries and visceral structures, lacking a communicating branch with the cervical spinal nerve, although all typical branches including the jugular nerve, carotid sinus branch, internal and external carotid nerves, communicating branches to vagus, glossopharyngeal, hypoglossal, cranial laryngeal, pharyngeal branch of vagus nerves, and close relationship between CCG and the longus capitis muscle, vagus nerve, and internal carotid artery were almost consistently present among the ungulates. The site of origin and the number of the major nerves including jugular nerve, internal and external carotid nerves extremely differed among the ungulates.

KEY WORDS: Anatomy; Bovine; Cranial cervical ganglion; Sympathetic nervous system.

\section{INTRODUCTION}

The cranial cervical ganglion $(\mathrm{CCG})$ is the uppermost ganglion of the paravertebral sympathetic trunk which innervates the neck, face, intercranial structure, and proximal part of the cervical region (Jenkins, 1987). A review of the available literature revealed that, although the macroscopic anatomical studies on the CCG, and its branches of the ungulates have been described in detail on the pig (Kabak et al., 2005), roe deer (Kabak \& Ounk, 2010), Angora goat (Ari et al., 2010), white yak (Shao et al., 2011), yak (Shao et al., 2007), Bactrian camel (CuiSheng et al., 1998), donkey (Ozgel et al., 2004), and dromedary camel (Nourinezhad et al., 2015), to date, it seems to be no article pertaining to detailed gross anatomy of the bovine CCG and its branches. Nevertheless, only scattered, very little, and fragmentary anatomical accounts of location, some neural connections with surrounding structures, size and shape of the bovine CCG have been presented only by drawing, but not by photographs in all veterinary texts and atlases.

Symptoms of the head and neck sympathetic denervation as Horner's syndrome vary intra- and interspecifically in the domestic ungulates, including horse, cow, sheep, and goat (De Lahunta, 1977; Smith \& Mayhew, 1977). As a basis for a better understanding and interpretation of the causes of species differences in Horner's syndrome, more detail and exact information concerning morphology and topography of the bovine CCG and its branches is needed. Hence, the main objective of this study was to document a detailed, colorful, illustrative description of the skeletotopy, syntopy, morphometry, and morphology of the bovine CCG and its branches. In addition, to comprehend comparative morphological of the CCG among ungulates more completely, our results were

\footnotetext{
* Division of Anatomy and Embryology, Department of Basic Sciences, Faculty of Veterinary Medicine, Shahid Chamran University, Ahvaz, Iran.

** D.V.M. Student of the Faculty of Veterinary Medicine, Shahid Chamran University of Ahvaz, Ahvaz, Iran.
} 
compared with findings of previously reported ungulates species.

\section{MATERIAL AND METHOD}

Fourteen sides of seven heads of young Holstein bulls were used in this study. The specimens were obtained from a local slaughterhouse without any external abnormality or pathology. The age of animals was estimated from the chronology of the eruption of the permanent incisors, ranged between 2 to 3 years. The animal's living weight (316-383 $\mathrm{kg}$ ) was computed based on carcass weight (190-230 kg). The head's weight was approximately $21 \mathrm{~kg}$. The heads were immersed in $5 \%$ formaldehyde solution. Holotopy, skeletotopy, and syntopy were considered in the present study in order to define exact and accurate topography of the CCG with its adjoining structures. Each ganglion was measured in terms of its length or long axis and width or short axis using a caliper. Dissection was performed under a floating arm fluorescent illuminated magnifier (2.5X). Digital images were taken by a digital camera (Canon, Tokyo, Japan, G9).

\section{RESULTS}

Shape and size of the CCG. The CCG was found to be constantly present on both sides of all specimens and the ganglion was enclosed by a fat connective tissue. The CCG was a very well developed structure, oval or roughly spindleshaped being widened at its dorsal pole (Figs. 1-5). In the right side of one specimen, the CCG became concave on its medial surface, and its lateral side tended toward convexity. The CCG measured approximately $10-12 \mathrm{~mm}$ in width and 20-25 mm in length.

\section{Topography of the CCG}

Holotopy: The CCG as a cephalic sympathetic ganglion was situated over the retropharyngeal region between the dorsal end of the stylohyoid bone at the level of its muscular angle. The long axis of the CCG was almost oblique, and the direction of the dorsal (proximal) pole was caudodorsal and pointed towards the petroocipital fissure, whereas the direction of the ventral (distal) pole was rostroventral and tipped towards the dorsal surface of the arytenoid cartilage (Fig. 2).

Skeletotopy: The CCG was positioned rostrally and medioventrally to the jugular process extremity. The CCG was placed close to the ventral surface of the caudolateral part of middle of the cranial base, ventromedial to the ven-

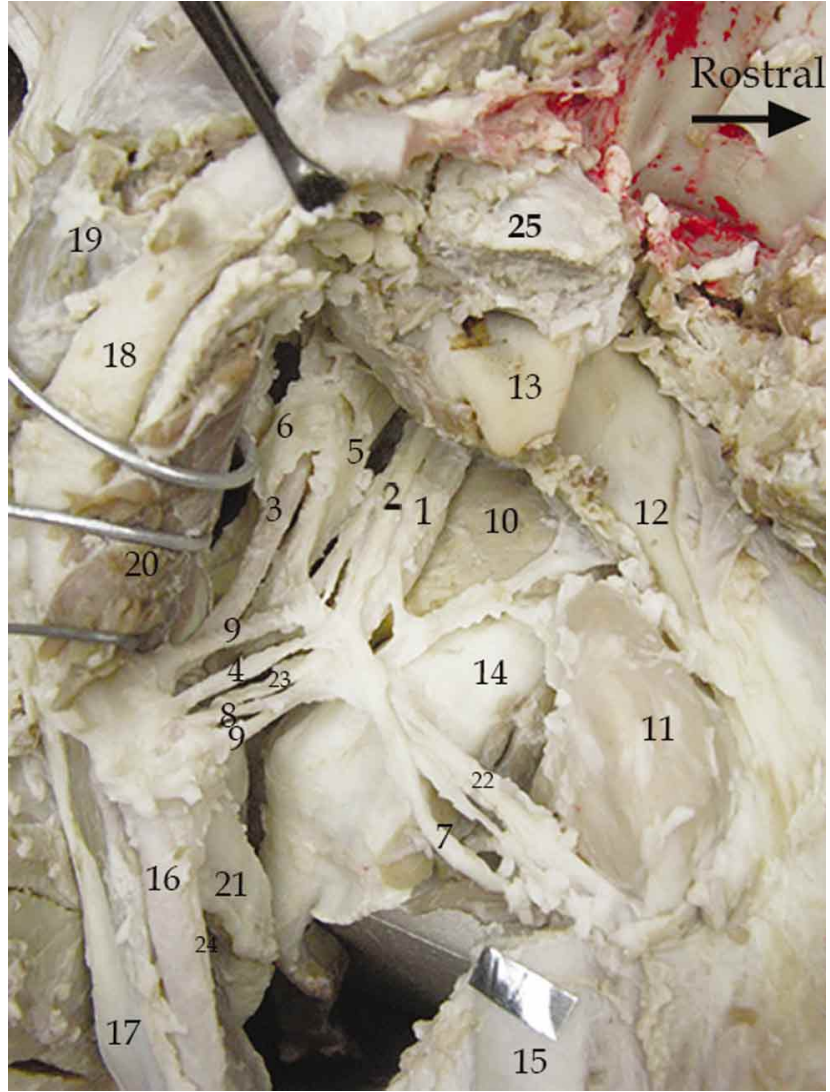

Fig. 1. The topography of the cranial cervical ganglion (CCG): right caudolateral view. The dorsal part of the stylohyoid bone has partially been removed. The digastric, caudal stylopharyngeus, occipitohyoid muscles, and maxillary artery have been displaced slightly caudal to display the CCG and branches with its surrounding arteries and nerves. The arteries and nerves have been also separated slightly from each other. (1) CCG; (2) Glossopharyngeal nerve; (3) Occipital artery; (4) Carotid sinus branch of the glossopharyngeal nerve; (5) Vagus nerve; (6) Hypoglossal nerve; (7) Pharyngeal branch of the glossopharyngeal nerve; (8) Ascending pharyngeal artery; (9) External carotid d nerve; (10) Longus capitis muscle; (11) Medial retropharyngeal lymph node; (12) Hamulus process of the pterygoid bone; (13) Ventral margin of the temporal bone; (14) Rectus capitis ventralis muscle; (15) Stylohyoid bone; (16) Linguofacial trunk; (17) Caudal belly of the digastric muscle; (18) Maxillary artery; (19) Occipitohyoid muscle; (20) Caudal stylopharyngus muscle; (21) Common carotid artery; (22) Pharyngeal branch of the vagus nerve; (23) External carotid nerve; (24) Linguofacial branch; (25) Dorsal extremity of the stylohyoid bone. Scale bar $=1 \mathrm{~cm}$.

tral margin of a large tympanic bulla (Figs. 1 and 2). The lateral surface of the central part of CCG was covered by one-third of the dorsal part of the stylohyiod bone after removal of the ramus of the mandible (Fig. 1). On the lateral side, the rostrodorsal pole of the CCG was covered by the ventral margin of the tympanic bulla after removal of the dorsal part of the stylohyoid bone (Fig. 2). 


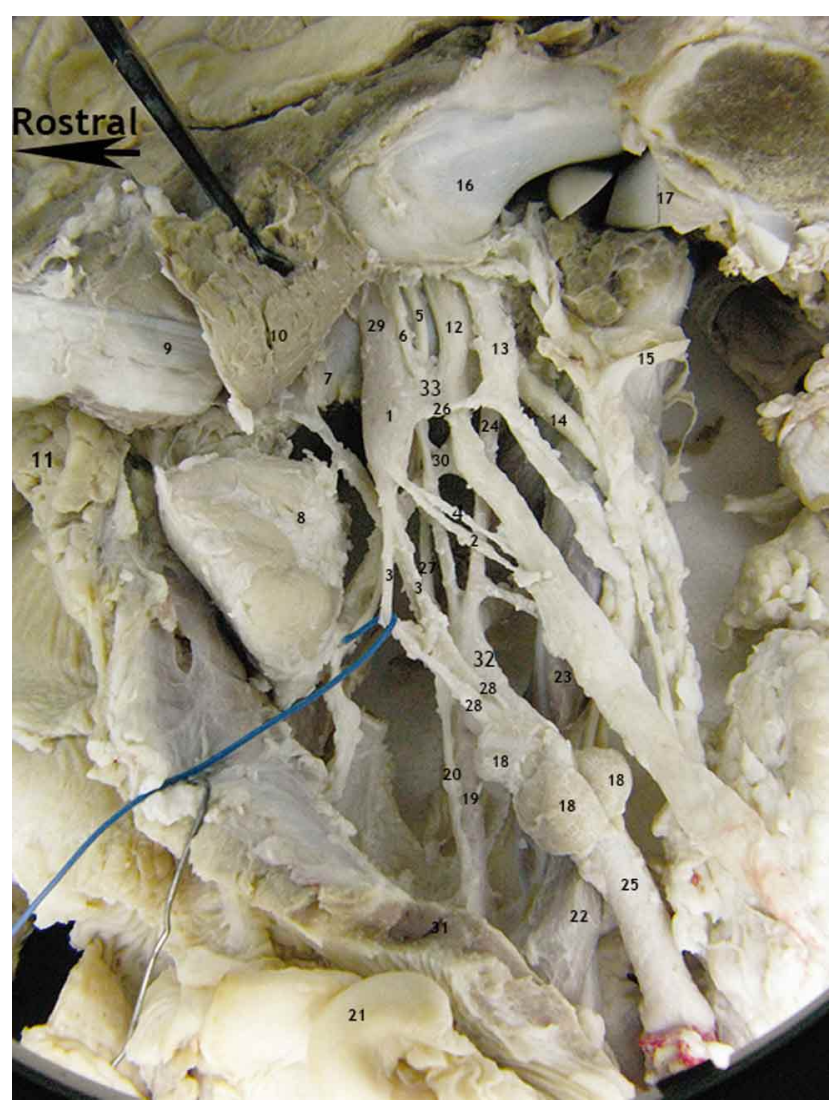

Fig. 2. The topography of the cranial cervical ganglion (CCG): caudomedial view. The longus capitis and rectus capitis ventralis muscles, and external carotid nerve have been displaced slightly rostral to display the CCG and its branches with its surrounding arteries and nerves. The pharyngeal wall has also been removed partly. (1) CCG; (2) Sympathetic trunk; (3) External carotid nerve; (4) Communicating branch between the CCG and vagus nerve; (5) Glossopharyngeal nerve; (6) Internal carotid artery; (7) Ventral margin of the tympanic bone; (8) Medial retropharyngeal lymph node; (9) Rectus capitis ventralis; (10) Longus capitis muscle; (11) Palatine tonsil; (12) Vagus nerve; (13) Hypoglossal nerve; (14) Accessory nerve; (15) Ventral branch of the first cervical spinal nerve; (16) Occipital condyle; (17) Atlas; (18) Mandibular salivary gland; (19) Linguofacial trunk; (20) Linguofacial branch; (21) Arytenoid cartilage; (22) Caudal belly of the digastric muscle; (23) Rostral belly of the digastric muscle; (24) Occipital artery; (25) Common carotid artery; (26) Communicating branch between the CCG and the hypoglossal nerve; (27) Ascending pharyngeal artery; (28) Glandular branch; (29) Internal carotid nerve; (30) Pharyngeal branch of the vagus nerve; (31) Pharyngeal wall; (32) Carotid sinus; (33) Communicating branch between the CCG and vagus nerve. Scale bar $=1 \mathrm{~cm}$.

Syntopy: The CCG was laterally surrounded by plenty of the fat mass but its glossy medial surface was clearly visible after removal of the longus capitis muscle. On the medial side, the CCG was located between the medial retropharyngeal lymph node and the longus capitis muscle
(Fig. 2). In the medial aspect, the CCG was dorsal to the pointed dorsal end of the mandibular salivary gland lying on the course of the medial surface of the common carotid artery near its transition to the external carotid artery (Fig. 2). On the lateral view, the CCG was situated caudomedial to a very large medial retropharyngeal lymph node (Figs. 1 and 2). On the lateral side, the ventral half of the CCG was constantly covered by the caudal stylopharyngeus muscle after removal of the dorsal part of the stylohyoid bone at the level of its muscular angle (Fig. 1). In the right side, the long axis of the lateral surface of the CCG was crossed by the glossopharyngeal which was only slightly rostral to the internal carotid artery (Fig. 1). The caudolateral surface of the CCG at its caudal margin was in a very close contact with the internal carotid artery throughout its course (Fig. 2). The CCG was about $3-4 \mathrm{~cm}$ dorsorostral to the angle of transition of the common carotid artery to the external carotid artery in the region between the internal carotid and ascending pharyngeal arteries (Fig. 1). On the lateral side, the CCG lay over the rostrolateral surface of the insertion portion of the longus capitis muscle and its fascia (Fig. 1).

\section{Branches of the CCG}

The CCG gave off the vascular, visceral, and communicating branches and received the cervical interganglionic branch.

Vascular branches of the CCG: Vascular branches accompanied with major blood vessels and their branches supplied the perivascular nerve plexuses to their distribution. The vascular branches that were distinguished in the bovine CCG were those accompanying the internal carotid, common carotid, and occipital arteries, carotid sinus, ascending pharyngeal, external carotid, linguofacial trunk, and branches of the ascending pharyngeal, caudal auricular, superficial temporal and maxillary arteries.

Internal carotid nerve: The nerve was the largest branch emerging from the CGG approximately $29-33 \mathrm{~mm}$ in length (distance between its caudodorsal extremity and floor of the cranial cavity) and 7-8 $\mathrm{mm}$ in width at its beginning. The nerve originated from the caudodorsal extremity of the CCG as a single trunk and then divided immediately into 6 to 8 branches within a common sheath, which varied in width (Figs. 3 and 4). The nerve was not a direct upwards continuation of the cervical sympathetic trunk and ran caudodorsally very closely alongside with the extra-cranial segment of the internal carotid artery over medial surface of the tympanic bulla to enter the cranial cavity through the petrooccipital fissure (Fig. 2). During its course, the nerve gave off no twigs to form a periarterial plexus around the extra-cranial segment of the internal carotid artery. One the 
medial side, the extra-cranial part of the internal carotid nerve was covered by the longus capitis muscle. One the lateral side, the whole extra-cranial part of the internal carotid nerve or approximately the proximal half of the internal carotid nerve, in some cases, was covered by the tympanic part of the tympanic bulla (Fig. 2). The intracranial part of the internal carotid nerve was closely attached to the periosteum of the tympanic bone (Fig. 3).

External carotid nerve: The nerve was approximately 30 $32 \mathrm{~mm}$ in length and $3-4 \mathrm{~mm}$ in width at its beginning which emerged from the rostroventral margin of the CCG as a single nerve, ran little rostral to the internal carotid artery and medial to the ascending pharyngeal artery to their origin from the common carotid artery. Then the nerve, after a short course, or just slightly before reaching at the level of the transition of the common carotid to the external carotid artery exactly near the origin of the ascending pharyngeal artery, was divided into two branches (Figs. 2 and 3). The distinct branch coursed ventrally and rostrally accompanying the linguofacial trunk (Fig. 2). Another branch curved laterally and rostrally accompanying the maxillary artery.

The following vascular and visceral branches were detached from the external carotid nerve:

Occipital branch: One or two thin large branches emerged from the external carotid nerve and reached the occipital artery at the level of its origin from the common carotid artery.

Carotid sinus branch: Small branches derived from the terminal part of the external carotid nerve to the vicinity of the origin of the internal carotid and occipital arteries from the dorsal surface of the common carotid as a carotid sinus.

Ascending pharyngeal branch: The vascular branches to the origin of the ascending pharyngeal artery derived from the medial surface of the external carotid nerve or from the ascending pharyngeal artery. A rich periarterial plexus was formed around the branches of the ascending pharyngeal artery as ascending pharyngeal plexus (Fig. 3). The following nerve branches accompanied the branches of the ascending pharyngeal artery to its neighboring organs (Fig. 3).

Pharyngeal branch: The two or three branches derived from the external carotid plexus accompanying the pharyngeal branch of the ascending pharyngeal artery to the pharynx (Fig. 3).

Tonsillar branch: A branch originated from the ascending

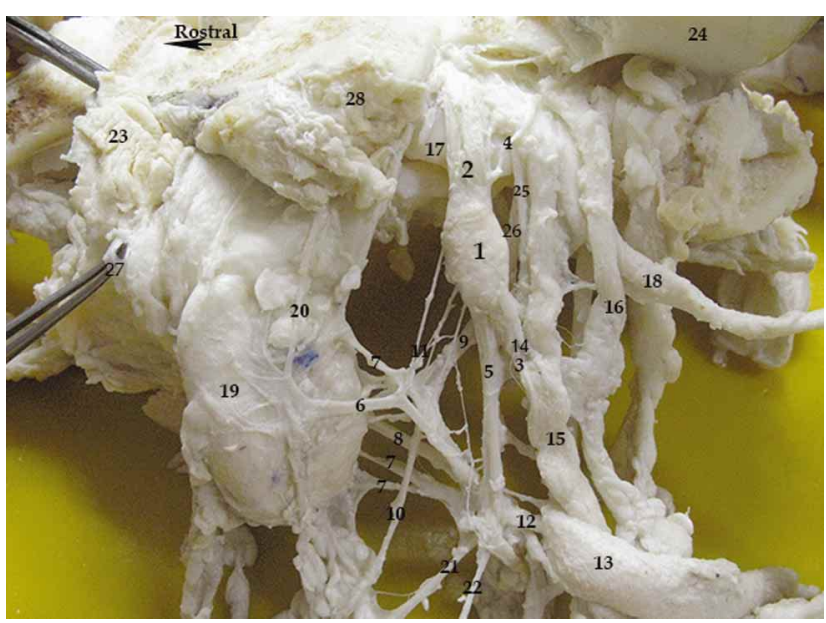

Fig. 3. The topography of the cranial cervical ganglion (CCG): caudomedial view. The longus capitis and rectus capitis ventralis muscles, and part of the tympanic bone have removed to fully display the whole course of the internal carotid nerve and jugular nerve. (1) CCG; (2) Internal carotid nerve; (3) Sympathetic trunk; (4) Jugular nerve; (5) External carotid nerve; (6) Palatine branch of the ascending pharyngeal artery; (7) Lymphatic branch of the ascending pharyngeal artery; (8) Tonsilar branch of the ascending pharyngeal artery; (9) Pharyngeal branch of the glossopharyngeal nerve; (10) Pharyngeal branch of the ascending pharyngeal artery; (11) Nerve branches extended to branches of the ascending pharyngeal artery; (12) External carotid artery; (13) Common carotid artery; (14) Communicating branch between the CCG and the vagus nerve; (15) Vagus nerve; (16) Hypoglossal nerve; (17) Ventral margin of the tympanic bulla; (18) Accessory nerve; (19) Medial retropharayngeal lymph node; (20) Muscular branch of the ascending pharyngeal artery; (21) Lingual artery; (22) Facial artery; (23) Palatine tonsil; (24) Occipital condyle; (25) Internal carotid artery; (26) Glossopharyngeal nerve; (27) Terminal part of the tonsilar branch of the ascending pharyngeal artery; (28) Longus capitis muscle.

pharyngeal plexus accompanying the tonsillar branch of the ascending pharyngeal artery to the palatine tonsil (Fig. 3).

Lymphatic branch: Two branches originated from the external carotid plexus accompanying two or three retropharyngeal branches of the ascending pharyngeal artery to the medial retropharyngeal lymph node (Fig. 3).

Linguofacial branch: The nerve branch was one of the most distinct vascular nerve branches of external carotid nerve as a direct vetro rostral continuation of the external carotid nerve along the dorsomedial surface of the artery (Figs. 1 and 2). The vascular branch to the caudal auricular artery, superficial temporal artery, and the maxillary artery was the continuation of the external carotid nerve. The nerve branches passed over the dorsolateral surface of relevant arteries. 


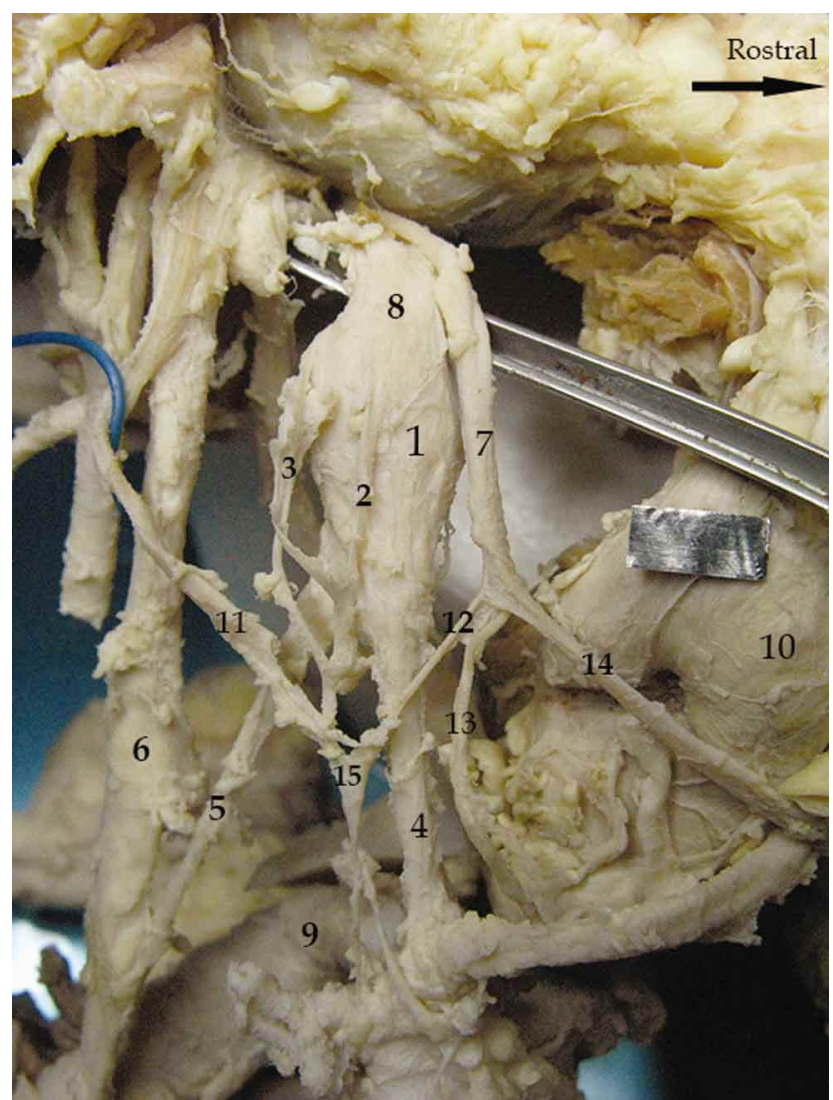

Fig. 4. The topography of the cranial cervical ganglion (CCG) of the bovine: right caudolateral view. The nerves have been slightly separated from each other; this has disturbed the normal relationships of the structures. The vagus nerve has also been displaced slightly caudal. (1) CCG; (2) Pharyngeal nerve of the CCG; (3) Pharyngeal branch of the CCG; (4) External carotid nerve; (5) Sympathetic trunk; (6) Vagus nerve; (7) Glossopharyngeal nerve; (8) Internal carotid nerve; (9) Common carotid artery; (10) Medial retropharyngeal lymph node; (11) Pharyngeal branch of the vagus nerve; (12) Pharyngeal branch of the glossopharyngeal nerve; (13) Carotid sinus branch of the glossopharyngeal nerve; (14) Pharyngeal branch of the glossopharyngeal nerve; (15) Pharyngeal plexus; (16) Common carotid artery. Scale bar $=1 \mathrm{CM}$.

Visceral branches of the CCG: Apart from all previous mentioned visceral branches which were carried through vascular branches to the medial retropharyngeal lymph node, palatine tonsils, and pharynx, there were following visceral branches:

Glandular branch: Two short branches were direct downward continuation of the external carotid nerve to the dorsal end of the mandibular salivary gland, lying on the course of the medial surface of the common carotid artery near its transition to the external carotid artery (Fig. 2).

Pharyngeal branch: In $30 \%$ of the cases, there appeared to be two long branches coming from the caudomedial margin of the central part of the CCG, at its caudal margin and turned laterally after passing over the medial surface of the internal carotid artery towards ventrorostally to help in the formation of the pharyngeal plexus either alone or in association with corresponding branches from the vagus and glossopharyngeal nerves. The plexus was over the lateral surface of the pharyngeal wall, medial to the caudal stylopharyngeus muscle, distal to the ventral pole of the $\mathrm{CCG}$, above the origin of the internal carotid and ascending pharyngeal arteries from the dorsal surface of the common carotid artery (Figs. 3 and 4). In $50 \%$ of the cases, two to three relatively long and thin branches originated from the lateral surface of the central part of the CCG and reached the pharynx either alone or in association with the respective branches of the vagus and glossopharyngeal nerves to constitute the pharyngeal plexus. The plexus was over the lateral surface of the pharyngeal wall, medial to the caudal stylopharyngeus muscle, distal to the ventral pole of the $\mathrm{CCG}$, above the origin of the internal carotid and ascending pharyngeal arteries from the dorsal surface of the common carotid artery (Fig. 4).

Laryngeal branch: In $30 \%$ of the cases, a long branch (20 $\mathrm{mm}$ in length) took origin from the rostroventral end of the CCG close to the point of entry of the sympathetic trunk and joined the site of the origin of the cranial laryngeal nerve from the vagus nerve (Fig. 5).

Palatine branch: One or three branches originated from the lateral surface of the rostroventral of the CCG or from the rostrodorsal margins of the CCG accompanying the palatine branch of the ascending pharyngeal artery to the soft palate (Fig. 3).

Muscular branch: A branch originated from the lateral surface of the rostroventral margin of the CCG accompanying the muscular branch of the pharyngeal branch of the ascending pharyngeal artery to the insertion portion of the longus capitis muscle (Fig. 3).

\section{Communicating branches of the CCG}

Jugular nerve: Jugular nerve was $2.1 \mathrm{~cm}$ in length, which originated from the caudomedial side of the internal carotid nerve, just about after emerging from the CCG. It coursed caudodorsally towards the jugular foramen passing over the medial surface of the most proximal part of the internal carotid artery, glossopharyngeal, vagus, and hypoglossal 
nerves. The jugular nerve exchanged delicate filaments with these nerves near their exits (Fig. 3).

Communicating branch to the vague nerve: Two or three small and stout twigs arose from the caudal margin of the middle part of the CCG joined the medial surface of the vagus nerve (Fig. 2). In $20 \%$ of the cases, a long branch emerged from the rostroventral end of the CCG, exactly near attachment of the sympathetic trunk to the CCG running along with the sympathetic trunk to communicate with the rostromedial margin of the vagus nerve (Figs. 2 and 3).

Communicating branch to the pharyngeal branches of the vague and glossopharyngeal nerves: In $30 \%$ of the cases, two long braches originated from the caudomedial margin of the central part of the CCG, at its caudal margin and turned laterally to communicate with the pharyngeal branch of the vagus and glossopharyngeal nerves (Fig. 4). In $50 \%$ of the cases, from the lateral surface of the central part of the, CCG two or three relatively long and thin branches communicated with the pharyngeal branches of the vagus and glossopharyngeal nerves while passing over the lateral surface of the internal carotid artery and the sympathetic trunk and medial to the glossopharyngeal nerve a little distal to the ventral pole of the CCG (Fig. 4).

Communicating branch to the hypoglossal nerve: In 25 $\%$ of the cases, a short and stout branch detached from the caudal margin of the middle part of the CCG connected to the medial surface of the hypoglossal nerve (Fig. 2).

Communicating branch to the cranial laryngeal nerve: In $30 \%$ of the cases, a long branch (20 mm in length) took origin from the rostroventral end of the CCG close to the point of entry of the sympathetic trunk and joined the origin of the cranial laryngeal nerve from the vagus nerve (Fig. 5). The CCG did not communicate with the carotid sinus branch of the glossopharyngeal nerve, the accessory nerve, and the cervical spinal nerves (Figs. 2-4).

\section{Cervical interganglionic branch or cervical sympathetic} trunk: The most rostral part of the sympathetic trunk was separated from the rostromedial margin of the vagus nerve over the medial surface of middle part of the caudal belly of the digastric muscle, approximately $2.5-4.5 \mathrm{~mm}$ distocaudal to the ventral pole of the CCG. Then the nerve passed over the medial surface of middle part of the internal carotid and the occipital arteries and the hypoglossal nerve joined the rostroventral end of the CCG (Figs. 1, 2 and 4).

The most rostral part of the cervical interganglionic branch little distal to the ventral pole of the CCG laterally coursed by the pharyngeal branch of the vagus nerve, while passing rostrally toward the pharynx (Figs. 2, 4 and 5). The most rostral part of the cervical interganglionic branch was covered laterally by the caudal styopharyngeus muscle after removal of the stylohyoid bone (Fig. 1). The width of the cervical interganglionic branch, at its point of the attachment to the CCG was approximately $3-4 \mathrm{~mm}$.

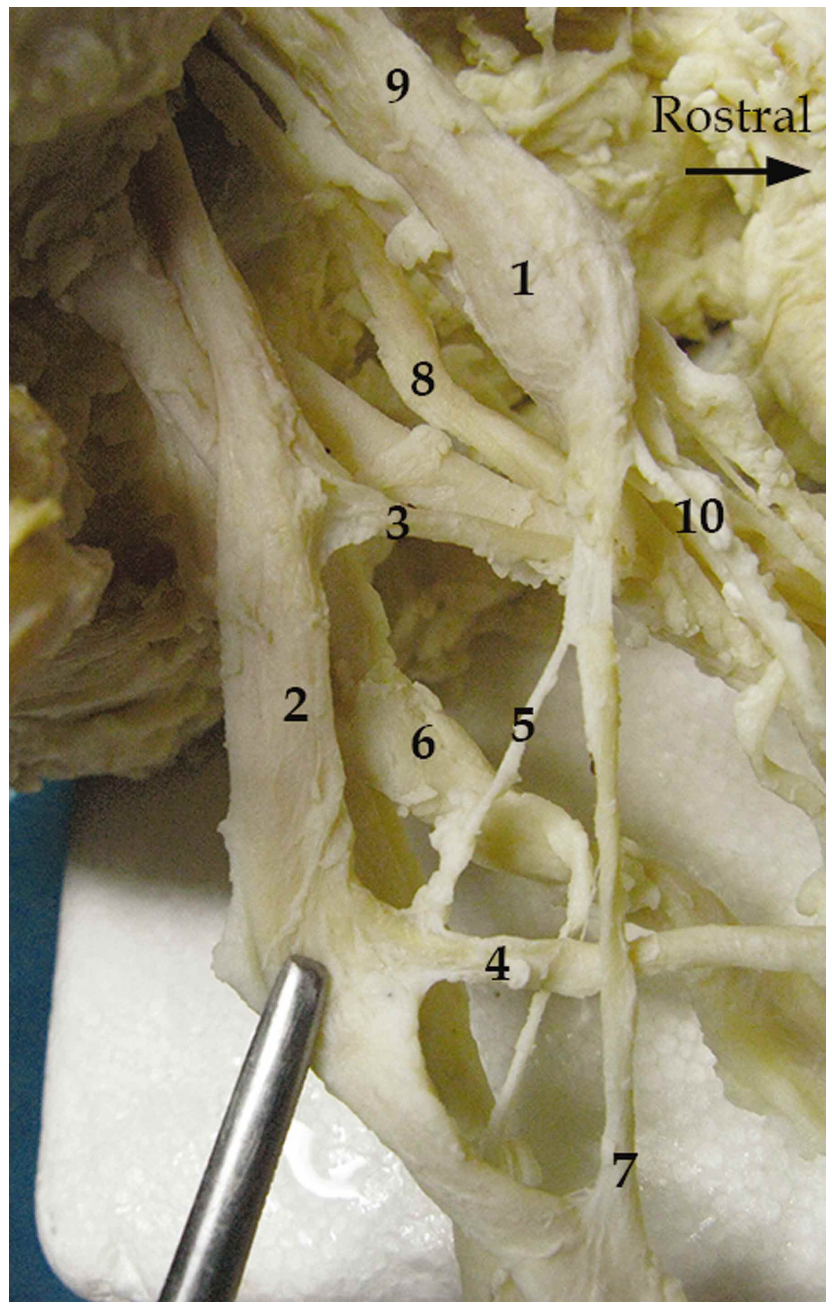

Fig. 5. The topography of the cranial cervical ganglion (CCG) of the bovine: right caudolateral view. The nerves have slightly been separated from each other; this has disturbed the normal relationships of the structures. The vagus nerve has been displaced slightly caudal. (1) CCG; (2) Vagus nerve; (3) Pharyngeal nerve of the vagus nerve; (4) Cranial laryngeal nerve; (5) Communicating branch between the CCG and cranial laryngeal nerve; (6) Hypoglossal nerve; (7) Sympathetic trunk; (8) Glossopharyngeal nerve; (9) Internal carotid nerve; (10) External carotid nerve.

\section{DISCUSSION}

Shape and size of the CCG. In the present study, the shape of the CCG was noted oval or roughly spindle being widened 
at its dorsal pole. The shape of the CCG was found to be an arciform in the white yak, oval in the roe deer, pig, and most dromedary camels, irregular fusiform or flattened in the donkey, rectangular in the Angora goat, and fusiform in the Bactrian camel, horse (Sisson et al., 1975), domestic ruminants (Sisson et al.), yak, some dromedary camels, and sheep (May, 1964). Accordingly, the shape of the CCG in the bovine was more similar to that of Bactrian camel, horse, yak, domestic ruminants, and yak.

In the right side of one specimen, the CCG became somewhat concave on its medial surface, and its lateral side tended toward convexity. However, in some cases of the dromedary camels CCG was somewhat concave on its lateral side and became convex on its medial side.

The general orientation of the CCG in the bovine was different from the other reported ungulates. The long axis of the CCG was almost oblique, and the direction of the dorsal pole was caudodorsal, whereas its ventral pole was rostroventral. It seems that in the reported ungulates species, the long axis of the CCG was somewhat oblique, but the direction of the dorsal pole was rostrodorsal and its ventral pole was caudoventral.

According to previous published data regarding $\mathrm{CCG}^{\prime}$ dimensions, the length and the width of the CCG varied among animal species (Table I). Consequently, the largest CCG in size belongs to the bovine. On the other hand, some authors have stated that there is a positive correlation between body size and CCG length or size in the horse (Fioretto et al., 2007), and Angora goat, which corresponded with the present study. Nevertheless, a negative correlation was not reported in the roe deer and dromedary camel.

Table I. Comparison in the dimensions of the cranial cervical ganglion in various species.

\begin{tabular}{ll}
\hline \multicolumn{1}{c}{$\begin{array}{c}\text { Length and width } \\
\text { of the CCG }\end{array}$} & \multicolumn{1}{c}{ Species } \\
\hline $20-25 \mathrm{~mm} \times 10-12 \mathrm{~mm}$ & This study \\
$14-18 \mathrm{~mm} \times 6-8 \mathrm{~mm}$ & $\begin{array}{l}\text { Dromedary camel } \\
\text { Calf (Getty, 1975) } \\
15 \mathrm{~mm} \times 8 \mathrm{~mm}\end{array}$ \\
$15 \mathrm{~mm} \times 5 \mathrm{~mm}$ & Sheep \\
$8 \mathrm{~mm} \times 3 \mathrm{~mm}$ & Goat \\
$10 \mathrm{~mm} \times 4 \mathrm{~mm}$ & Young pig (Getty, 1975) \\
$26.3 \mathrm{~mm} \times 6.4 \mathrm{~mm}$ & Adult horse (Fioretto et al., 2007) \\
$13.84 \mathrm{~mm} \times 3.67 \mathrm{~mm}$ & Adult roe deer \\
$15-20 \mathrm{~mm} \times 4-6 \mathrm{~mm}$ & Bactrian camel \\
$19.72 \mathrm{~mm} \times 7.65 \mathrm{~mm}$ & Yak \\
$17.3 \mathrm{~mm} \times 8.0 \mathrm{~mm}$ & White yak \\
$8-14 \mathrm{~mm} \times 2-4 \mathrm{~mm}$ & Angora goat \\
\hline
\end{tabular}

Syntopy of the CCG. In the present study, the ventral half of the CCG was laterally covered by the caudal stylopharyngeus muscle after removal of the dorsal part of the stylohyoid bone. On the contrary, the largest part of the dromedary CCG was laterally located under the medial retropharyngeal lymph but the rostral half of the CCG was also covered laterally by the origin of the digastric muscle. The CCG was covered laterally by the mandibular salivary gland in the Bactrian camel and donkey, or covered by wholly or partially with the occipitohyoid muscle in the sheep (Appleton \& Waites, 1957) or $95 \%$ of the CCG in the white yak and $75 \%$ of the CCG in the yak was covered by the stylohyoid muscle. Therefore, the syntopy of the lateral surface of the CCG relative to the muscles and glands exhibits extreme variability among ungulates species.

In the current investigation, the long axis of the lateral surface of the CCG was crossed by the glossopharyngeal nerve. Dougherty et al. (1958) reported that the glossopharyngeal nerve lay on the lateral surface of the sheep CCG. Sisson et al. in the bovine, Cui-Sheng \& Xie (1998) in the Bactrian camel, Habel (1970) in his book on guide to the dissection of domestic ruminants, and Budras et al. (2012) in the schematic illustration supplied in the horse indicated that the pharyngeal branch of the vagus nerve passed lateral to the CCG. In the dromedary camel, the lateral surface of the CCG was crossed obliquely by the hypoglossal nerve (Nourinezhad et al.). It can be concluded that the lateral surface of the CCG exhibited almost constant relationship with the glossopharyngeal nerve among the ungulates regardless of the dromedary camel.

According to the descriptions of previous articles and photographs, the caudodorsal margin or the caudal margin of the CCG was parallel to the internal carotid artery in the yak white yak, pig, and roe deer. Habel in the dissection of domestic ruminants described that the internal carotid artery runs dorsally and caudomedially to the CCG in domestic ruminants. Moreover, in the description of the dromedary camel (Nourinezhad et al.) and the schematic illustration supplied in the Bactrian camel (Cui-Sheng et al., 1998) defined that the lateral surface of the rostral half of the CCG crossed vertically by the internal carotid artery. The CCG was very close caudal to the internal carotid artery in the donkey (Ozgel et al.) and in the schematic illustration supplied in the horse (Budras et al.). In the horse, the CCG was in close apposition with the internal carotid artery (Sisson et al.). However, the schematic illustration supplied in the sheep (Appleton \& Waites) depicted that the long axis of the CCG was crossed by the ascending pharyngeal artery. The sheep CCG was medial to the condylar artery (May). In the present study, the caudolateral surface of the CCG, at its caudal margin was in very close association with the internal 
carotid artery. Although there was almost constant close relationship between the CCG and the internal carotid artery, the course pattern of the internal carotid artery to the CCG exhibited tangible differences among the ungulates.

In this study, the CCG was about $3-4 \mathrm{~cm}$ dorsorostral to the region between the internal carotid and ascending pharyngeal arteries. Such a topographic trait was reported in the roe deer. Nevertheless, the CCG was situated in the area between the internal carotid and occipital arteries in the description of the donkey (Ozgel et al.) and in the schematic illustration supplied in the horse (Budras et al.). In the pig, the CCG was medial of the common root established by the internal carotid and occipital arteries (Kabak et al.).

Based on available schematic illustration and photographs, the CCG lay in very close opposition to the vagus nerve in the white yak, dromedary camel, roe deer or lay a little rostral to the vagus nerve in the donkey, Bactrian camel, Angora goat, yak, horse (Budras et al.) and pig, in which the former pattern was similar to that of the present finding.

The CCG is related to the lateral surface of the longus capitis muscle in the yak, white yak, Bactrian and dromedary camels, and in the schematic illustration supplied in the horse (Budras et al.), in which such a syntopy was in concurrent with the present finding.

According to the accounts in the previous paragraphs regarding syntopy of the CCG, it can be inferred that there is almost a quite constant close relationship between the CCG and the longus capitis muscle, vagus nerve, and internal carotid artery among the ungulates.

One of the remarkable topographical relations of the bovine CCG which requires attention is close relation of the CCG to the medial retropharyngeal lymph node. Such a syntopy of the CCG was not described in the available literature. On the other hand, it should be kept in mind that the medial retropharyngeal lymph node varies in position in some ungulates. In the dromedary camel, the lymph node is not located on the dorsal wall but on its latero-ventral surface in the cranial division of the cervical region (Gavrylin et al., 2013). More to the point, inflammation of the medial retropharyngeal lymph node may involve the CCG and its branches. Because in cattle, the vagus nerve in the retropharyngeal region may be affected by the cellulitis and medial retropharyngeal lymph node abscessation secondary to injuries to the pharynx (Davidson et al., 1981).

Skelototopy of the CCG. Based on Table II, the exact position of the CCG shows great variation among ungulates species. However, surprisingly, all published data on morphology of CCG in these animals concluded that the location of CCG is similar among species (Cui-Sheng et al.; Ozgel et al.; Kabak et al.; Shao et al., 2007, 2011; Ari et al.; Kabak \& Onuk). As shown in Table II, the bovine CCG was located slightly more rostral than that of in the pig, roe deer, horse, and Angora goat even though the location of the bovine CCG was very similar to that in the dromedary camel.

Previous publications indicated that approximately $25 \%$ and $5 \%$ of the rostrodorsal part of CCG in the yak and white yak was laterally covered by the tympanic bulla, respectively. In the horse, the CCG was located ventrocaudally to the tympanic bulla (Fioretto et al.). However, our finding indicated that in some cases the caudodorsal pole of the bovine CCG was laterally covered by the ventral margin of the tympanic bulla, which is more similar to that in the white yak.

In the present study, the CCG was laterally concealed by one-third of dorsal part of the stylohyoid bone, whereas in the dromedary camel only rostrodorsal part of the CCG was laterally covered by the angle of the stylohyoid bone.

The pig CCG was located medial of the jugular process extremity (Kabak et al.), whereas in the present study, the CCG was positioned rostrally and medioventrally to the jugular process extremity.

The skelototopical differences of the bovine CCG including its positional shift and bony structures lateral to the CCG show the bovine CCG seems not to be laterally accessible whereas, in the sheep the ganglion is less accessible and the CCG is finally exposed by cutting through the occipitohyoid muscle which overlies it laterally (Appleton \& Waites). A thorough understanding of species topographical differences of the CCG is important for lateral surgical approach of the CCG in neurophysiological studies and during anatomical dissection courses.

\begin{tabular}{ll}
\hline Position of the CCG & \\
\hline Middle of the cranial base & This study \\
Caudal to the cranial base & Dromedary camel \\
Ventral to the atlanto-occipital joint & Horse (Getty, 1975) and Angora goat \\
Ventral to the atlas & Roe deer and pig \\
Ventral to the atlanto-axial joint & Donkey \\
Not recorded exactly & White yak and yak \\
\hline
\end{tabular}


Internal carotid nerve. It appears that the internal carotid nerve tends to be extremely variable in the number of nerve branches among various species, both individually and specifically. In this study, the internal carotid nerve was composed of seven to eight branches. On the contrary, the internal carotid nerve is composed of one branch in most dromedary camels, or two branches in the horse (Sisson et al.) and most pigs (Kabak et al.), or three branches in most Angora goats, most roe deer, some pigs (Kabak et al.), or four to five branches in the white yak, most yaks, and some pigs (Kabak et al.), or five to six branches in the Bactrian camel.

The absence of the internal carotid plexus affirmed in the pig, and most roe deer, which concurred with the present finding. However, the presence of the internal carotid plexus is expounded in the dromedary camel, white yak, yak, horse, donkey and Bactrian camel.

The internal carotid nerve of the bovine $(2.2 \mathrm{~cm}$ in length) seems to be shorter than that of in the dromedary camel $(2.5-4 \mathrm{~cm})$, yak $(3-3.5 \mathrm{~cm})$, and white yak $(2-2.5 \mathrm{~cm})$. This may indicate the bovine seems to be closer to the below of the cranial base than that of in the dromedary camel, white yak and yak.

External carotid nerve. In this study, the external carotid nerve was composed of a single branch emerging from the rostroventral margin of the CCG. On the other hand, review literature revealed that the site of the origin and the number of branches of the external carotid nerve varied intra- and interspecifically among the ungulates. The external carotid nerve is composed of one branch in the Angora goat, donkey, some roe deer, dromedary camel, and horse (Sisson et al.), or two branches in most roe deer, Bactrian camel, white yak, yak, and most pigs (Kabak et al.), or 3 branches in some pigs (Kabak et al.). Therefore, the number of branches of the external carotid nerves in the bovine is very similar to that of in the Angora goat, donkey, horse, and dromedary camel.

The external carotid nerve emerged from the lateral and ventral of the cranial part of the CGG in some roe deer or from the lateral and ventral of the caudal part of the CGG in most roe deer, or from the rostroventral and caudolateral aspects of the CCG in the Bactrian camel, or from the caudoventral and caudomedial aspect of the CCG in the pig (Kabak et al.), or from the caudal half of the CCG in the Angora goat, or from the caudoventral and caudolateral aspects of the CCG in the white yak, yak, or from the rostroventral margin of the CCG in the donkey, or from the mediorostral surface of the CCG in most roe deer, or from the medial surface of the rostral half of the CCG in some roe deer.
The point of division of the external carotid nerve exhibited significant differences among species. The external carotid nerve existed originally as two branches in most roe deer, while the nerve emerged from the CCG as single branch and then ramified into two branches in some roe deer, in which this pattern was noted in all bovine examined.

The distribution of the external carotid nerve in the bovine was remarkably different from that of the reported ungulates species. We found a great expansion of vascular and visceral branches from the external carotid nerve and its branches to the adjacent structures, especially in terms of nerve branches extended to the ascending pharyngeal artery and its branches to reach the palatine tonsil, pharynx and medial retropharyngeal lymph node. Such a description was neither discussed nor illustrated in the available literature. Therefore, wider distributions of the external carotid nerve and its subsidiary vascular plexus may be correlated with well-developed salivary glands, lymphocenters of the head, and masticatory muscles involved in the highly synchronized activity of eructation and rumination.

Carotid sinus branch. In the literature, the carotid sinus branch of the CCG was demonstrated as one branch of the external carotid nerve detaching from the caudoventral margin of the CCG in the Bactrian camel, yak, white yak, and roe deer. Abdel-Magied \& Drommer (1989) indicated that the carotid sinus of the dromedary camel innervated by two to three tiny branches from the CCG and their illustration showed that the nerve springs from the ventral pole of the CCG. In addition, Sisson et al. also described that fine branches ramified from the CCG to the area of the carotid sinus in the horse, but did not define the exact point of the origin of the carotid sinus branch. Ozgel et al. did not mention anything about the nerve to the carotid sinus of the donkey. In the dromedary camel, the carotid sinus branch was as a nerve arising mainly from the medial aspect of the ventral pole of the CCG or from the external carotid nerve. In the pig, Kabak et al. indicated that the carotid sinus received nerve branches not only from the CCG but also directly from the external carotid nerve. In the current study, the carotid branch nerve derived from the external carotid nerve. Therefore, the interspecies variations of the site of origin of the carotid sinus branch among the ungulates may be related to locational variations of the carotid sinus in the origin from the common carotid artery. The carotid sinus was present at the origin of the internal carotid artery in the dromedary camel (Etemadi, 1975) or at the origin of the occipital artery in the ox, sheep, and horse (Sisson et al.).

The pharyngeal branch was identified and named after comparison with given a description in the pig (Kabak et al.), roe deer and the schematic illustration supplied in 
the domestic ruminants and pig (Sisson et al.). In some cases of the roe deer, one branch originated from the ventral or lateral of the cranial part of the CCG or from the lateral or ventral of the caudal part of the CCG to pharynx. In some cases of the pigs, one branch emerged from the lateral or medial surface of the central part of the CCG or from the lateral surface of the caudal part of the CCG (Kabak et al.). The schematic illustration supplied in the horse, domestic ruminants, and pig showed that the pharyngeal branch coming from the lateral surface of the central part of the CCG (Sisson et al.). In the present study, the pharyngeal branch of the CCG originated from the caudomedial margin of the CCG or from the lateral surface of the central part of the CCG.

Laryngeal branch. Although a branch extending between the ventral margin of the CCG and the cranial laryngeal nerve was observed in the roe deer and pig, theses study were not called the nerve as a laryngeal branch. Such a branch was noted in some cases of the present study.

From comparative anatomical viewpoint, it seems that in some ungulates the laryngopharyngeal branch of the CCG provides innervation of the larynx and pharynx instead of pharyngeal and laryngeal branches of the CCG. Only in three articles the laryngopharyngeal branch was shown and described in the ungulates. In the dromedary camel, the laryngopharyngeal branch originated from the different part of the CCG or from the sympathetic trunk close to the point of its attachment to the CCG and communicated to the cranial laryngeal nerve. In the Angora goat arose from the caudal half of the CCG and communicated to the cranial laryngeal nerve. Moreover, Sisson et al. introduced the laryngopharyngeal branch as a nerve branch of the CCG in horse but did neither describe nor illustrate. In the present study, the nerve was not observed.

Jugular nerve. The site of the origin, the number of nerve branches, and neural connection of the jugular nerve varied intra- and inter-specifically among the ungulates. The jugular nerve was composed of a single nerve in most reported ungulates, including in the roe deer, donkey, pig, Bactrian camel (in 4 specimens), dromedary camel and Angora goat, which was similar to that in this study. Nevertheless, the nerve was composed of two branches in 6 specimens of the Bactrian camel, yak, and white yak.

The nerve was noted detaching from the dorsal pole of the CCG in in the roe deer, donkey, pig, Angora goat, Bactrian and dromedary camels or from the internal carotid plexus in the white yak, and yak. However, the jugular nerve originated from the internal carotid nerve in the animals presently studied.

Generally, the jugular nerve communicated with the vagus and the glossopharyngeal nerves in the roe deer, donkey, pig, Bactrian camel, yak, white yak, and Angora goat, which was concurrent with the present study, but the bovine jugular nerve also provided extra communicating branch with the hypoglossal nerve. Such a finding was neither discussed nor illustrated in the available literature. On the other hand, the jugular nerve in the dromedary camel was communicated only with the vagus nerve.

Communicating branch to the cranial nerves. The communicating branches between the CCG and the last four cranial nerves and/or with their branches exhibited intraand inter-species variations (Table III). Ozgel et al. did not

Table III. Comparison in the communicating branch from the CCG to the cranial nerve or with their branches in various species.

\begin{tabular}{ll}
\hline $\begin{array}{l}\text { Communicating branch from the CCG to } \\
\text { cranial nerve }\end{array}$ & \multicolumn{1}{c}{ Species } \\
\hline $\begin{array}{l}\text { Glossopharyngeal nerve } \\
\text { Pharyngeal branch of the glossopharyngeal } \\
\text { nerve }\end{array}$ & $\begin{array}{l}\text { Pig, horse (Getty, 1975), white yak and yak } \\
\text { This study, goat (Getty, 1975), white yak, yak and Bactrian camel }\end{array}$ \\
$\begin{array}{l}\text { Carotid sinus branch of the glossopharyngeal } \\
\text { nerve }\end{array}$ & $\begin{array}{l}\text { Dromedary camel, ox (Getty, 1975), roe deer and horse (Getty, } \\
1975)\end{array}$ \\
Vagus nerve by communicating branches & $\begin{array}{l}\text { This study, dromedary camel, pig, Bactrian camel, yak, goat, } \\
\text { horse (Getty, 1975), roe deer and sheep (May, 1964) }\end{array}$ \\
Pharyngeal branch of the vague nerve & $\begin{array}{l}\text { This study, pig, horse (Getty, 1975), roe deer and domestic } \\
\text { ruminants (Getty, 1975) }\end{array}$ \\
Cranial laryngeal nerve & $\begin{array}{l}\text { Dromedary camel, roe deer, pig, horse (Getty, 1975) and Angora } \\
\text { goat }\end{array}$ \\
Accessory nerve & $\begin{array}{l}\text { Pig, roe deer and horse (Getty, 1975) } \\
\text { This study, pig, roe deer, white yak, yak, Bactrian camel and } \\
\text { horse (Getty, 1975) }\end{array}$ \\
\hline Hypoglossal nerve &
\end{tabular}


Table IV. Comparison in the communicating branch of the CCG to the cervical spinal nerve (CSN) in various species.

\begin{tabular}{ll}
\hline Communicating branch with the CSN & \multicolumn{1}{c}{ Species } \\
\hline Not seen & This study, white yak, yak and Angora goat \\
1 CSN & $\begin{array}{l}\text { Domestic ruminants (Getty, 1975; Habel, 1970), Bactrian camel, } \\
\text { donkey, pig (Getty, 1975), sheep (May, 1964), dromedary came] }\end{array}$ \\
& (Nourinezhad et al., 2015) and some roe deer \\
$1-2 \mathrm{CSN}$ & Horse (Getty, 1975) and pig (Kabak et al., 2005) \\
\hline
\end{tabular}

study the communicating branches between the CCG and the cranial nerves. The communicating branches from the bovine CCG to the cranial nerves and their branches were more similar to that in the Bactrian camel, yak and whit yak, with two differences: the absence of a communication branch with the pharyngeal branch of the vagus nerve in the yak, white yak, Bactrian camel, and the presence of a communicating branch with the glossopharyngeal nerve in the yak and white yak.

Lacking a communicating branch of the CCG to the accessory nerve was indicated in the yak, white yak, Angora goat, Bactrian and dromedary camels, which was concordant with the present finding. In addition, the communicating branch of the CCG to the vagus nerve seems to be almost constant in all reported ungulates species. The communicating branch of the CCG to the hypoglossal nerve seems to be almost constant in most reported ungulates species regardless of the Angora goat, and dromedary camel. Viewed as a whole, it seems that the expansion of the range of the communicating branches with the cranial nerves and branches in the bovine CCG was much narrower than that of in the pig, horse and roe deer.

Communicating branch to the spinal nerve. The CCG generally exhibited communicating branches at least with one of the first two cervical spinal nerves in various ungulates species (Table IV). In the present study, the bovine CCG did not communicate with any cervical spinal nerve, which corresponded with the previous finding described in the yak, white yak, and Angora goat. Perhaps the main conclusion to be drawn from the above data is that the presence and range of expansion of the communicating branch from the CCG to the cervical spinal nerve might be closely correlated with the positional variations of the CCG of the ungulates species. In other words, the positional change of the bovine CCG (more rostral) seems to be resulting in a lack of communicating branch to the cervical spinal nerve and contributing only to the head organs.

Cervical sympathetic trunk or cervical interganglionic branch. According to previous published data, the separation of the vagus and the most rostral part of the cervical sympathetic interganglionic branch occurred distal to the distal ganglion of the vagus nerve at the variable distance in the pig (Sisson et al.) and some yaks, or rostral to the distal ganglion of the vagus nerve at the variable distance in most yaks and white yaks, or at the level of the atlantoaxial joint in the Bactrian camel (Cui-Sheng et al.) and some dromedary camels, or at the medial surface of the origin of the occipital artery in the horse and domestic ruminants (Habel; Sisson et al.), or medial to the parotid salivary gland in the sheep (May), or distal to the ventral pole of the CCG at the viable distance in most dromedary camels. In the present study, the separation took place over the medial surface of the middle part of the caudal belly of the digastric muscle 2.5$4.5 \mathrm{~cm}$ distal to the ventral pole of the CCG. Therefore, the separation of the vagosympathetic trunk in the most proximal part of the neck exhibited great variability among the ungulates. It should also be kept in mind that the distal ganglion of the vagus nerve was not observed in the domestic ruminants (Sisson et al.).

\section{ACKNOWLEDGEMENTS}

The authors wish to appreciate the financial support from the Research Affairs of Shahid Chamran of Ahvaz. We are grateful to Mr. R. Fathi for his technical assistance.

NOURINEZHAD, J.; MAZAHERI, Y. \& SABERIFAR, S. Topografia y morfologia del ganglio cervical craneal bovino y sus ramos. Int. J. Morphol., 34(2):545-556, 2016.

RESUMEN: Se realizó un estudio anatómico submicroscópico detallado del ganglio cervical craneal (GCC) y sus ramos, con las estructuras adyacentes, mediante el examen de 14 hemicabezas, correspondientes a siete cabezas de ganado Holstein, bajo aumento, para proporcionar descripciones completas; además se tomaron fotografías a color de la ubicación, su relación con estructuras vecinas y la morfometría y morfología del GCC y sus ramos. Se compararon los resultados obtenidos relacionados con los nervios, incluyendo las arterias carótidas interna y externa; los datos morfológicos obtenidos del GCC de otros ungulados tal vez aclaren la anatomía comparativa detallada del GCC entre los ungulados. Encontramos diferencia significativas en la morfología del GCC y sus ramos en comparación con otros ungulados 
reportados en la literatura, particularmente en la dirección de los polos ventral y dorsal del GCC, siendo estos caudodorsal y rostroventral respectivamente, presentándose más grande y ligeramente más rostral, cubierto lateralmente por la parte dorsal del hueso estilohioídeo y el músculo estilofaríngeo caudal. Se evidenció una estrecha relación del GCC con los nodos linfáticos retrofaríngeos mediales, con distribuciones más amplias del nervio carotídeo interno y el plexo adyacente a las arterias y estructuras viscerales, careciendo de un ramo comunicante con el nervio espinal cervical. En todos los ungulados se encontraron consistentemente todos los ramos nerviosos típicos, incluyendo el nervio yugular, el ramo del seno carotídeo, los nervios carotídeos interno y externos, los ramos comunicantes para el nervio vago, glosofaríngeo, hipogloso, laringeo craneal, ramo faríngea del nervio vago, y la estrecha relación entre el GCC y el músculo largo de la cabeza, el nervio vago y la arteria carótida interna. Se determinaron diferencias importantes en el sitio y origen de la mayoría de los nervios, incluyendo el nervio yugular y los nervios carotídeos interno y externos.

PALABRAS CLAVE: Anatomia; Bovino; Ganglion cervical craneal; Sistema nervioso simpatico.

\section{REFERENCES}

Abdel-Magied, E. M. \& Drommer, W. Structure of the carotid sinus of the dromedary camel (Camelus dromedarius). Anat. Histol. Embryol., 18(4):316-26, 1989.

Appleton, A. B. \& Waites, G. M. A surgical approach to the superior cervical ganglion and related structures in the sheep. J. Physiol., 135(1):52-7, 1957.

Ari, H. H.; Soyguder, Z. \& Cinaroglu, S. Macroanatomy of the cranial cervical ganglion in Angora goats. Vet. Med., 55(8):389-93, 2010.

Budras, K. D.; Sack, W. O. \& Röck, S. Anatomy of the Horse. 6th ed. Hannover, Thieme, 2012.

Cui-Sheng; Wang, J. L. \& Xie, Z. M. The gross anatomy of the cranial cervical ganglion and its branches in the Bactrian camel (Camelus bactrianus). Vet. Res. Commun., 22(1):1-5, 1998.

Cui-Sheng \& Xie, Z. M. Gross anatomy of the accessory nerve and vagus nerve of the head and cranial neck region in the Bactrian camel. Vet. J., 155(3):317-21, 1998.

Davidson H. P.; Rebhun, W. C. \& Habel, R. E. Pharyngeal trauma in cattle. Cornell Vet., 71(1):15-25, 1981.

De Lahunta, A. Veterinary Neuroanatomy and Clinical Neurology. Philadelphia, Saunders, 1977.

Djallal Eddine, R. \& Hocine, B. Features topography and macrostructure of lymph nodes in Camels (Camelus dromedarius). Online J. Anim. Feed Res., 3(2):106-10, 2013.

Dougherty, R. W.; Habel, R. E. \& Bond, H. E. Esophageal innervation and the eructation reflex in sheep. Am. J. Vet. Res., 19(70):115-28, 1958.
Etemadi, A. A. Carotid body of Camelus dromedarius. Acta Anat. (Basel), 92(1):110-21, 1975.

Fioretto, E. T.; de Abreu, R. N.; Castro, M. F.; Guidi, W. L. \& Ribeiro, A. A. Macro- and microstructure of the superior cervical ganglion in dogs, cats and horses during maturation. Cells Tissues Organs, 186(2):12940, 2007.

Getty, R. Sisson and Grossman's the Anatomy of the Domestic Animals. $5^{\text {th }}$ ed. Vol. 1 \& 2. Philadelphia, Saunders, 1975.

Habel, R. E. Guide to the Dissection of Domestic Ruminants. $2^{\text {nd }}$ ed. Ithaca, Robert E. Habel, 1970.

Jenkins, T. W. Functional Mammalian Neuroanatomy. $2^{\text {nd }}$ ed. Philadelphia, Lea \& Febiger, 1978.

Kabak, M.; Orhan, I. Ö. \& Haziroglu, R. M. Macro anatomical investigations of the cranial cervical ganglion in domestic pig (Sus scrofa domesticus). Anat. Histol. Embryol., 34(3):199-202, 2005.

Kabak, M. \& Onuk, B. Macro anatomical investigations of the cranial cervical ganglion in roe deer (Capreolus capreolus). Ankara Üniv. Vet. Fak. Derg., 57:1-6, 2010.

May, N. D. S. The Anatomy of the Sheep. $2^{\text {nd }}$ ed. Queensland, University of Queensland Press, 1964.

Nourinezhad, J.; Mazaheri, Y. \& Biglari, Z. Detailed Anatomy of the Cranial Cervical Ganglion in the Dromedary Camel (Camelus dromedarius). Anat. Rec. (Hoboken), 298(8):1479-91, 2015.

Ozgel, O.; Kurtul, I. \& Dursun, N. On the gross anatomy of the cranial cervical ganglion of the donkey (Equus asinus) in Turkey. Vet. Res. Commun., 28(4):261-6, 2004.

Shao, B. P.; Ding, Y. P.; Xie, Z. H.; Yu, H. X.; Brand-Saberi, B. \& Wang, J. L. The cranial cervical ganglion and its branches in the yak (Bos grunniens). Vet. J., 173(1):174-7, 2007.

Shao, B. P.; Ding, Y. P. \& Wang, J. L. The cranial cervical ganglion and its branches in the White yak (Bos grunniens). Anat. Histol. Embryol., 40(5):321-5, 2011

Smith, J. S. \& Mayhew, I. G. Horner's syndrome in large animals. Cornell Vet., 67(4):529-42, 1977.

Correspondence to:

Jamal Nourinezhad. D.V.M. Ph. D.

Division of Anatomy and Embryology

Department of Basic Sciences

Faculty of Veterinary Medicine

Shahid Chamran University of Ahvaz

Ahvaz

IRAN

Email: j.nourinezhad@scu.ac.ir

Received: 05-11-2015

Accepted: 01-03-2016 